\title{
Ho Chi Minh's Thought on Medical Ethics and its Significance for Vietnam Today
}

\author{
Dr. Nguyen Minh Tri \\ Ho Chi Minh City University of Technology (HUTECH), Ho Chi Minh City, Vietnam. \\ E-mail:nm.tri@hutech.edu.vn
}

\begin{abstract}
Ho Chi Minh is one of the revolutionary leaders who discussed ethics the most, being himself a great example of practising revolutionary ethics. Especially, He paid great attention to medical ethics. The job of physicians is special and noble, and directly related to the health and lives of people, so it requires each cadre and staff of the health sector to improve their expertise, raising their sense of responsibility, being committed to their service and having the ethics of the job. Ho Chi Minh's thought on medical ethics bears profound scientific content and great practical significance. Vietnamese physicians today need to study and follow the thought, and need to practice and improve themselves more and more to be deserving examples of what He taught - "Physicians shall be like caring and gentle mothers".
\end{abstract}

Keywords: Physicians, medical ethics, Ho Chi Minh thought.

\section{Introduction}

In Ho Chi Minh's ideological system, there were thoughts about morality in general and ethics in particular. Ho Chi Minh's thought about the ethics of a physician has profound scientific content and great practical significance. There have been many research works on Ho Chi Minh's thoughts on ethics of physicians and the application of such ideas in Vietnamese physicians. However, the value in Ho Chi Minh's thought about the ethics of a physician still needs to be studied and clarified, especially, it needs to be better used by Vietnamese physicians.

Two research questions are revealed as following:

Question 1. What is the content of Ho Chi Minh's thoughts on medical ethics?

Question 2. What is the meaning of moral ideas for Vietnam today?

\section{Ho Chi Minh's thoughts on medical ethics}

The Vietnamese people have a tradition of respecting the religion, a very respectful respect for teachers: teachers and physicians. The Vietnamese people have placed the position of a literacy teacher on par with their father, a physician like their mother, because the profession of a physician is a profession of healing and saving people, as the second mother of the sick. In order to take care of human health, it is necessary to have a team of qualified and professional physicians with professional ethics.

After the establishment of the Democratic Republic of Vietnam (September 2, 1945), the Party and the Government trained and fostered a contingent of nurses, doctors, doctors, physicians to treat medicine with medicine and medicine. male, traditional Chinese medicine and advanced medical facilities, with high medical ethics and medicine. Professor Ho Dac Di, Professor, Doctor Ton That Tung, Doctor Dang Van Ngu, Doctor Vu Dinh Tung, Professor Dang Van Chung ... are 
leading professors and doctors of the current Vietnamese medicine industry. great merit and great merit in the country's revolutionary cause.

Ho Chi Minh is a person who is very concerned about medical ethics, a good physician and a gentle mother devoted to the patient. In his letter to the Military Medical School in 1946, at the 1948 Military Medical Conference, the 1953 National Health Conference, he emphasized the virtue of sacrifice, devotion to service as well as a sense of discipline and responsibility. health workers. In a letter to the August 1948 Military Medical Conference, Ho Chi Minh wrote: "A physician is not only responsible for curing illnesses but also supporting the morale of the sick" (Minh, 1995, p.395). According to him, in order to fulfill the noble task of saving people, the physician must have the task of "uplifting the spirit of the sick", must have a love for the profession, consider the sick patient as being sick himself, must consider the care. caring for the patient is the reason for life, the joy, the happiness of oneself; must have medical expertise, be a spiritual friend, help motivate the patient. The physician must promote professional ethics, must practice ethics in a completely voluntary, non-profit manner; the happiness of the sick person must be considered as one's own happiness; must be very wholehearted, molded in myself the love of the job; must be passionate about work, constantly strive, practice to improve professional qualifications. In a letter to the 1953 National Health Officer Conference, Writer: "The health of the staff and the people is guaranteed, the more enthusiastic the spirit is. The fuller spirit and health, the more victorious the resistance will be, and the more successful national construction will be. That task has two parts: Disease prevention is just as essential as treating illnesses. In order to fulfill that task, health workers need to: love the sick person like siblings. It is necessary to conscientiously and diligently serve the people"(Ho, 1996a, p.11). At the Medical Officer Conference (2-1955), he wrote: "The sick people entrust their fate to the aunts and uncles. The government entrusts the girls and the uncle to cure diseases and take care of the health of the people. It is a glorious task. Therefore, officers need to love and take care of the sick like siblings and treat them in pain like they do. A physician must be like a model, that statement is very correct"(Ho, 1996a, p.476). In this thought, he affirms that the physician has a noble mission and great responsibility towards man and society; Medical ethics education is a content that should be interested in any period or any society. Thus, Ho Chi Minh has clarified the importance of improving medical ethics as well as the importance of constantly improving the professional expertise of physicians.

As for the national health development path, he said: "Medicine must be based on the principles of science, the nation, the masses. My fathers in the past had a lot of valuable experiences on how to cure diseases with our medicines, traditional Chinese medicine. In order to expand the scope of medicine, women and teachers should also focus on researching and combining oriental and western medicines "(Ho, 1996a, p.476). Western medicine cures many diseases, but there are also diseases that cannot be cured; our medicine can cure many diseases, but there are also diseases that cannot be cured by western medicine ... Each side has advantages, two advantages combined, it can cure the people, the people, the clothes. for building socialism. The physician must study traditional medicine, our physicians must also study western medicine ... Our physicians and physicians both serve the people, like people with two hands and two hands working together, they can work well. Therefore, it is necessary to unite from top to bottom, from bottom up, to unite our medicines and medicines into one block to heal the people. This thought is the idea of combining modern medicine with traditional medicine. This thought is the right orientation for the Party and State in the development of the health sector. 
Conscience is an aspect of physician ethics. In the Letter to the Military Medical Conference in August 1948, he wrote that the physician was not only responsible for curing illnesses but also supporting the sick people spiritually; "Herbalist cum from samples". The thought of "physician cum from motherhood" means that the physician must have a conscience and high responsibility towards the sick person like a mother to her child. The physician's conscience in relation to the patient is reflected in ethical behavior and moral affection. Moral behaviors are behaviors with an internal motive that are consistent with the ethical requirements and norms of the society. The physician's moral affection is the driving force, the virtues have become habitual, motivating the physician to act in accordance with the ethical standards of the society. Moral sentiment has the function of motivating a physician to practice ethical behavior and self-assessment of his or her ethical behavior. Conscience has the function of self-assessment of human moral behavior, so it is both an emotional phenomenon and an intellectual phenomenon. A clear professional conscience is the basis for forming the necessary qualities of a physician towards the patient (such as a gentle attitude, warmth when in contact with the sick person; diligence, suffering, conscientiousness. dedicated to the examination and treatment; old glasses, love for children, courtesy to women in social relations). The physician's conscience is also the basis for forming a deep sympathy for the patient's pain, from which arose love and attentive care for the patient; forming the virtues of need, thrift, integrity, righteousness, and carefree character of revolutionary morality in professional work. Conscience and duty are two aspects of dialectical unification in ethics of a physician. In this relationship, conscience is the content, obligation is the expression form of conscience defined by conscience. A physician cum model is also understood as a physician who is both ethical and professional.

According to President Ho Chi Minh, "virtue" is a measure of the physician's conscience and obligation towards the patient, is a basic requirement, is the physician's root; while "talent" is the professional capacity manifested in efficiency in caring for, protecting health and providing medical examination and treatment for the people. President Ho Chi Minh said that virtue and talent have a close relationship with each other. In that relationship, virtue must stand before talent, just as persevere must stand before professionalism; Therefore, there must be politics first, then expertise, politics is virtue, expertise is talent. Having talent but not virtue is corrupt ... He asserted: "Having talent must have virtue. There is no virtue, no virtue, corruption harmful to the water Having a virtue without being as talented as a Buddha sitting in a temple does not help anyone "(Ho, 1996b, p.184). In the medical profession, ethics is the basis and driving force for all behaviors of physicians towards patients. When there is virtue, talent contributes to making virtue greater and brighter. On the contrary, if a physician is only talented and lacks virtue, that talent is also in danger of being abused to serve the selfish attempt, harming the interests of the patient.

According to President Ho Chi Minh, the profession of physician is a special profession, directly related to human health and destiny. The lives and health of the people are entrusted to the physician, so the society always has very high requirements on expertise and especially the spirit of service and ethics of each physician. Physicians must be rich in compassion, not only having the task of healing, but also raising the morale of the sick while they are in difficult circumstances. According to him, the medical ethics of a physician is the moral conscience, the duty and duty of the physician. The analyst, the nurse is not only a profession, but also an obligation. Maintaining and fostering the nation's health, the nurse must take an important part. In order to fulfill the noble task of both "healing" and "uplifting the spirit of the sick", it requires health workers to have a love for the profession, love their profession, and consider taking care of people's health as reason, is joy, is my own happiness. In the physician's activities, 
the relationship between the physician and the patient is the primary and special relationship, that is, the patient is always in a passive position, depending on the physician, they also worry about health. health and the cost of money to cure, but there are also many people willing to spend a lot of money hoping to get health back, they have no expertise so completely depend on the doctor. As a physician, if they do not have a conscience or responsibility, it is very easy for them to take advantage of this situation to make it difficult for the patient, not enthusiastic, complete or controlled by money. Thus, in order to fulfill their duties well, the physician needs to converge both professional capabilities and professional ethics in order to fulfill his mission of curing human diseases.

Faced with the negative status of medical ethics in hospitals with many complicated manifestations today, "the principles of democratic centralization, self-criticism and criticism in many places are both neglected in implementation and not yet in practice. is specified as a basis for inspection and supervision"(Communist Party of Vietnam, 2012, p.24), President Ho Chi Minh's teaching: medicine cum from the sample must be defined as the invariant for the medical industry to train regularly, used to improvise. Although in the market mechanism, many humanto-person relationships are being commercialized, the love of doctors - patients are easily forgotten, but modern society always requires physicians to make efforts to preserve keep and promote the humanitarian and noble humanity in their labor and profession.

\section{The significance of Ho Chi Minh's ideology on medical ethics in current Vietnamese physicians}

The issue of improving the revolutionary morality for health workers has been deeply concerned by the Party, State, and related agencies. Under the light of Ho Chi Minh's ideology, the Party's guidelines and lines, the State's legal policies, the health sector have built a system of rules and standards on medical ethics through various stages of development. sufficient, comprehensive, rich, deeply humanistic. The Party and State have issued many documents on policies and laws related to the development of the health sector, building a workforce for the health sector such as: Directive 04 / CT- BYT on medical ethics; Decision No. 2088 / QD-BYT (1996) includes 12 articles on ethical standards of health workers; Decision No. 2526 QD-BYT (1999) on the inspection and evaluation of professional work, focusing on evaluating the implementation of specific standards to strive for ethics... These documents have been and are has been implemented and achieved tangible results. Most of the medical staff in Vietnam performed well the standards of medical ethics according to Ho Chi Minh thought.

However, besides that positive side, the professional ethics of a part of medical staff is deteriorating. Due to the impact of the socio-economic life, on the flip side of the market economy, medical ethics must also undergo ups and downs, even at times of recession and degradation. The state of "Communist Party of Vietnam, 2012, p.15) is happening in a large number of officials. Party members and physicians. The phenomenon of irresponsibility of health workers on duty, harms the lives and health of patients. In particular, there is a discrimination against patients, people with money are cared for, cared for wholeheartedly, well prescribed with good medicine, and the poor are discriminated against, indifferent, not cared for. . The moral degradation in a large part of physicians has negatively affected the protection and care of the people's health and the development of the health sector. To push back the moral degradation of the medical profession, the team of physicians must study and follow Ho Chi Minh's thought of medical ethics. They need to strive to become a physician of virtue, tolerance, and love for the sick like a gentle mother. This is a very glorious task but also extremely difficult for health workers. According to Le Ngoc Trong: "The biggest and hottest challenge is the need 
to improve medical ethics before the economy operates under the market mechanism. The phenomenon of hidden fees appears to be a painful existence and is eroding the conscience and morality of many medical practitioners"(Phuc, 2008, p.65). In order to improve effectiveness in applying Ho Chi Minh's ideology on medical ethics, health workers in the current period need to focus on the following contents:

First, it is necessary to strengthen medical ethics education for the contingent of people working in the health sector. President Ho Chi Minh pointed out that: The revolutionary morality did not fall from heaven. It is due to the daily struggle and training that develops and reinforces. Just as the brighter the gem, the brighter the gold, the clearer it is. At the same time, he also said: "In order to wash away the evil traces of the old society, to practice revolutionary morality, we must work hard to study, cultivate and self-reform to progress forever. If you do not try to improve, it means regression, it is backward"(Ho, 1996c, p.284). Medical ethics education for health workers is especially important. Health education must be carried out regularly and seriously while the medical staff is still in training at medical schools and throughout the practice. Ethics does not come naturally, it is only built up and formed through educational paths. Medical schools, medical establishments, and hospitals need to consider medical ethics education as one of the tasks associated with training, management of professional activities, management of professional activities; It is necessary to create favorable conditions for each physician to practice and cultivate ethics in their professional activities, their profession, in their living relationships.

Medical ethics of physicians is always associated with competence and expertise. If a physician gives wrong diagnosis, incorrect treatment and unfortunate consequences, then they cannot be a physician with medical ethics, dedicated to the patient. At the same time, if we want to educate others to live morally, the person who works in education must live ethically. Ethical education is the job of the whole society, each person. Both the leaders and the people are both the subject and at the same time the object of moral education. Every Vietnamese person can do a good deed to become a good person and become a moral example. Therefore, President Ho Chi Minh reminded his staff: "The examples of good people doing good works in all shapes and sizes are precious materials for you to build people. Each other is one of the best ways to build the Party, to build revolutionary organizations, to build new people, to a new life"(Ho, 1996d, p.558). Thus, in order to improve medical ethics for medical staff, first of all, teachers and leaders must be a moral example for students and subordinates to follow. Medical profession is a noble profession, honored by the society, physicians must constantly study, improve their professional qualifications, practice medical ethics. As Vu Hoai Nam emphasizes: "Medicine is an industry directly related to human health and life. This is the most valuable capital, so it requires more people working in the medical industry to have special moral qualities"(Nam, 2014, p.31). Therefore, health workers themselves must always self-cultivate and practice medical ethics, learn and absorb the quintessence of modern medicine and inherit traditional traditional medicine. Health workers must love people, tolerate tolerance, always encourage and help patients, they must be dedicated to their jobs, passionate about work, and constantly strive to improve their professional qualifications. In today's market economy, they need to study and apply medical ethics and depending on their positions to facilitate the completion of their assigned tasks, which is to show the sense of responsibility for their profession, carry out his teachings.

Second, it is necessary to diversify forms of ethical education for physicians. Traditional forms of education such as propaganda and teaching ethical standards of physicians. This learning is done through training sessions, periodical short-term classes. In the classrooms, it is 
necessary to inform and promptly provide all physicians new requirements, problems arising from medical examination and treatment practice in the country as well as in the world. Physicians need to update achievements, examples of medical ethics to study and also criticize unethical and irresponsible behaviors. Give explanations, assessments, and personal suggestions about emerging ethical problems to find ways to overcome. In terms of practice, thoroughly grasping Ho Chi Minh's thought, revolutionary morality was not reduced from heaven, it was formed and developed by continuous training and cultivation. It is necessary to promote ethical education for primary physicians right in the course of practice, medical examination and treatment, and implementing their relationships both as physicians, as well as as citizens. In that sense, the health sector, medical facilities, and hospitals need to associate ethical education with creating favorable conditions in the practice of physicians, helping physicians to train and demonstrate medical ethics through social relationships, with patients, with colleagues and with oneself. In addition, to encourage physicians to participate in training classes, scientific research activities, socio-political activities (such as free medical examination and treatment for the poor in remote and isolated areas, and voluntary blood donation, charity...). All of the above movements and activities are very necessary, each form of education has a certain role and position, but each medical facility, each hospital needs to proactively and actively create a lot. form, many specific measures to educate, thereby improving the quality and efficiency of ethical education for physicians in our country today.

Third, it is necessary to promote proactivity and positivity and create favorable conditions for physicians to self-educate, self-train and cultivate morality. In order to improve the effectiveness of ethical education for current physicians, in addition to promoting and improving the quality of educational forms and measures, it is necessary to encourage proactivity, activeness and facilitation. favorable conditions for physicians to educate, practice and cultivate morality by themselves. The ethical self-education of physicians has a special irreplaceable place. In the process of self-education, the object turns itself into a "subject", actively receives external influences to educate and self-educate, this is a very necessary element in cultivating morality. of the physician. To do this requires the subject (ie the physician) to have a strong will, high will and determination, to overcome themselves, to overcome their own limitations. In order to effectively educate the physician's ethics, the physician himself must be aware of the requirements of the society and the collective, must have an ideal of life, professional responsibility and conscience, and know how to comply. adhering to the principles and standards of society, resolutely fighting the negatives, strongly supporting the positive in relationships with patients, with colleagues and with oneself.

The relationship between a physician and a patient is the one through which the physician's ethics is shown most directly and primarily. This relationship governs all other relationships of the physician. According to the general principle of the World Medical Council, in relations with patients, the physician must acknowledge and respect the rights of the patient. They have the right to health protection and care, the right to access medical services, the right to freedom of choice of doctors, the right to make decisions with themselves. In all circumstances, the physician must act in the interests of the patient, not do anything harmful to the patient or aggravate his condition. The physician must conscientiously give medical examination and treatment, take care of the patient, not discriminate against the patient, and not cause troubles to the patient. In the examination and care of patients, physicians must be considerate, polite, must explain the disease situation to patients and their family members to understand to cooperate in treatment, dissemination of benefits policies and regimes. obligation, encouragement, comfort, and 
encouragement to practice. To do these things, the physician needs to have good professional skills plus the mind of the physician, with the moral upbringing of the physician, which is the process of self-cultivation and self-training.

In the relationship between physicians and colleagues, physicians need to see a shared responsibility to strive for professional values. It is kindness, a clear conscience, a spirit of mutual support, a humble consideration of caring for each other. The first colleague of the physician is their masters, leading them into their profession, they need to respect and gratefully strive to be worthy of masters in medical examination and treatment. people. It is necessary to well implement President Ho Chi Minh's advice: "First of all, be honest, solidarity - unity is our strength. Solidarity between old and new cadres. Solidarity among all people in the health sector, from ministers, vice ministers, doctors, pharmacists to helpers. Because job positions differ, everyone is an essential part of the health sector, in serving the people "(Minh, 1996a, p.476). Thus in the relationship with colleagues, the physician himself needs to respect the skills and contributions of his colleagues, have good will, solve and support all problems in the working process, attach importance to sharing information with colleagues. This will help develop professional capacity, build solidarity, trust, and support each other, thereby helping to fulfill the tasks of each individual and the team.

In order to improve the effectiveness of medical ethics self-education activities of physicians, it is necessary to deeply realize the purpose and meaning of self-education activities, build the will and importance of self-education and self-training to improve your medical ethics. Based on the results of medical ethics education of the units, the guidance and assistance of colleagues, physicians need to deeply grasp the functions and responsibilities assigned, along with the content, methods and methods of self-education, self-fostering their own capacity; need self-study and self-training to improve professional ethics. The plan for self-education and selftraining of medical ethics of physicians should be built according to a strict process, the content of self-education must be comprehensive in terms of knowledge, experience, and professional skills to principles, rules and standards of medical ethics. Physicians need to direct their self-education activities to specific contents according to their professional responsibilities and tasks; It is necessary to have a spirit of self-training and self-criticism to overcome and eliminate the attitudes and behaviors of oneself which are inconsistent with the ethical standards required in professional activities at the grassroots units. Self-education, self-training is a meticulous and persistent process, so it is forbidden to be impatient, burning up the stage. The physician needs to be serious with himself, actively persevere in implementing the set plan with the appropriate content and self-education methods. The nature of this process is to well resolve the relationship between self-education and medical ethics education, turn the educational process into selfeducation, and develop and improve the ethical qualities of medical practitioners people.

\section{Conclusion}

Medical profession is a noble profession honored by society. Physicians must constantly study to improve their professional qualifications and practice medical ethics. In the present conditions, it can be said that Ho Chi Minh's thoughts on medical ethics are a guideline to help Vietnam build up basic views which have the meaning to guide the development of modern medicine and a preeminent health sector, meeting the increasing demands in the cause of health protection and care for the people, towards a sustainable society. 


\section{Acknowledgement}

All authors contributed equally to the conception and design of the study.

\section{References}

1. Communist Party of Vietnam. (2012). The Fourth Event Deed of the XI Central Executive Committee. Hanoi: National Politics.

2. Communist Party of Vietnam. (2016). Document of the 12 th National Congress of the Party. Hanoi: National Politics.

3. Dong, L. V. (2015). Ethical education for physicians in Vietnam in the current period. Philosophy doctoral thesis. Hanoi: Hanoi National University.

4. Hellmut, K. (2010). Ho Chi Minh - A chronicle. Hanoi: World.

5. Nam, V.H. (2014). "Improve medical ethics of the current military physicians ", Journal of Party Construction, No. 9.

6. Minh, H.C. (1995). Complete set, Volume 5. Hanoi: National Politics.

7. Minh, H.C. (1996a). Complete set, Volume 7. Hanoi: National Politics.

8. Minh, H.C. (1996b). Complete set, Volume 8. Hanoi: National Politics.

9. Minh, H.C. (1996c). Complete set, Volume 9. Hanoi: National Politics.

10. Minh, H.C. (1996d). Complete set, Volume 12. Hanoi: National Politics.

11. Jame, L. (1967). Ho Chi Minh. Pari: Ed. Seuil.

12. Pham, S. C. (2008), Cultural Diplomacy "For one copy Vietnamese identity in the international arena". Hanoi: The World Publishing House

13. Pham, G. K. (2015). Comprehensive Vietnamese diplomacy in times integration period. Hanoi: National politics - Truth.

15. Pierre, B. (2007). Ho Chi Minh: A Biography. Cambridge

University Press.

16. Song, T.(2005). Ho Chi Minh - A brilliant thinker. Hanoi: Theory.

17. Tran, T. H. M. (2014). Diplomatic culture of Vietnam, Topic scientific research at ministerial level, the agency in charge of the Cultural External Relations Department UNESCO.

18. Trong, L. N. (1997). Medical ethics, Hospital management. Hanoi: Medicine.

19. William, J. D. (2001). Ho Chi Minh: A life. New York: Hyperion. 